\title{
Surviving, but not thriving: the politics of care and the experience of motherhood in academia
}

This article considers the challenges of juggling the demands of motherhood in the experience of early career researchers operating in the British neoliberal academy, and suggests opportunities for alliance and resistance. Scholarship examining questions of labour in the neoliberal university (Evans 2010, Lynch 2010, Morrish 2015) has made evident the effects of metrics, managerial rationalities, institutional structures and performances of equality (Tzanakou 2019) on marginalised academics. Furthermore, scholarship on gendered and racialised labour in the academy (Arday and Mirza 2018, Bhopal 2018, Gabriel and Tate 2017, Gqola 2018) has made visible the enforcement of structural inequalities in the distribution and undertaking of academic labour, its institutional visibility and resulting immobility. The typical narrative of academic success is undergirded by a specific form of resilience: a politics of coping that is dictated by neoliberal structures which prioritise particular forms of work and recognise only certain forms of commitment as valid or valuable. In this ecology, the affective labours of mothers in academia are often occluded.

We write this article together, as recent new academic mothers, in order to explore forms of solidarity. We are interested in thinking about how motherhood and related caring responsibilities create a particular, precarious positioning in the university, one that raises important questions about ways of working in our pedagogy, writing, research and artistic practice.

Academia creates the expectation of structural compliance, even though it paradoxically also demands intellectual agency. In this article, we offer an intersectional consideration of the stakes of being a mother in academia. We talk about the guilt and shame that we juggle personally and professionally, examine the entanglements of these affects with our academic work, and discuss our place in the neoliberal institution. We articulate motherhood as a feminist strategy of resistance and allyship, and call attention to re-positioning that experience by developing new ways of moving forward, together.

\section{New mothers returning to academic work: shame and resilience}

Our return to work was frenetically overwhelming. We experienced feeling stuck between different forms of commitments, negotiated the personal rendered external to academic life, and encountered a lack of policy and process to support our transition. Meeting for a coffee in those first days, we felt held, heard, like allies. We listened to and felt each other's experiences - a vortex of delights, mundanities and pressures. It became evident we shared feeling stuck in our negotiating of personal and professional spaces. That conversation, however, was a moment of unsticking, a mutual recognition of our experiences shared privately in a space of safety and collegiality. We realised that these feelings are important, and that this conversation provided a validation of lived experience that had not previously been valued.

In dialogue, we understood that the feelings of being stuck also revealed shame in articulating this unease publicly. The lived experience of motherhood is dissonant with the 
ways in which the neoliberal university measures and values progress. The labour of teaching and administration and the pressures of metrics-valued research are shared challenges (particularly in the UK, and in other contexts where centralized academic measurement is now the norm), but for mothers with young children, they become ever-present and relentless alongside the navigating of our new responsibilities and mothering labour.

As new mothers, we cannot articulate our feelings of being overwhelmed, and of not being able to meet expectations as we did before, because of the fear of being viewed as not coping, or not doing our job 'well enough'. There is a silencing tension between the experience of being a new mother and the ambition for one's work and research as a female academic. It produces shame in both our roles: academic and mothering. Sara Ahmed speaks explicitly about sticky feelings, pointing to attachment as 'crucial to queer and feminist politics' (2004: 16). Shame can be ambivalent, but it can also work 'in complex ways to align individuals with and against others' (15). Within motherhood studies, this negotiation of shame and guilt (Sutherland 2010) has also shifted from the singularity of psychological or biologically determined frames, to the social model as a productive entanglement of affects. If shame also forecloses attachments, then paying attention to, and making space for those attachments, be they personal or professional, become fundamental work for new mothers. For us, finding each other at the return to work provided a space to tentatively share our feelings of inadequacy and guilt. It also afforded a chance for openly discussing how motherhood intersects with other forms of marginalisation.

Our conversations prompted a reflection on narratives of success in academia, so connected to presence, visibility and other forms of valuing commitment. We are mixed ethnicity Romanian and South African/Swiss migrants; talking about our experiences of motherhood alongside our experiences of cultural difference in the UK exposed for us what the whiteBritish university renders as personal or professional, as well as the structural assumptions about ways of working embedded in 'default' white British academia.

The precarity of academic life has never been more so. While we account for our intersectional identities and diverse backgrounds, we also acknowledge that our permanent institutional positions and supportive colleagues afford us privileges. If this is our experience, what might it be like for those in more precarious positions? How do we move forward in allyship? How might we share power in a way that dissolves the institutional codes which marginalise and dictate untenable structures of work? How could we continue to make a case for the ways in which the personal is not outside the professional, but rather shapes a practice that is generative? How do we take account of the relations that shape our ways of working and being in the commons of the institution?

\section{Affective Labour, motherhood and the neoliberal university}

The challenge in acknowledging that, as new mothers and academics, we may be surviving but not thriving is helpfully contextualised by the feminist academic Pumla Dineo Gqola's account of the difficulty of experiencing 'senses of inadequacy'. As a Black mother working in academia, Gqola speaks to the admission that motherhood means a change in how we practice and work, describing how she and her friend, also a new mother, would sit together and 'tentatively, playfully, [reassure] each other and [admit] senses of inadequacy that do not 
come easily to us highly accomplished professionals with PhDs who knew, before parenting, how to pack up our lives to live in countries whose languages we did not speak prior to arrival' (2018: 118). Gqola's intersectional discussion of motherhood offers a way of relearning how to navigate an academic's multiple spaces.

In her essays in Reflecting Rogue: Inside the Mind of a Feminist, Gqola acknowledges her 'own frustration with diminished work capacity as mother with a baby' (2018:185) and contextualises this experience against the background of the demands that academia makes on women, and on women of colour in particular. These lived experiences are also examined by Ahmed in her ongoing research on Complaint as Diversity Work; she argues that the institutional narratives surrounding complaint, much like diversity work, propose that 'to locate a problem is to become the location of a problem' (2017). Motherhood makes evident the affective entanglements of the university's narratives of compliance, as they play out through forms of labour and care within it. Teaching, like motherhood, requires dedication, commitment, presence. As new mothers back at work, we became aware of the structural pressures that render shared forms of labour both fundamental to the work we do as female academics, and unseen at the same time.

In speaking to other colleagues with children, particularly women, we were also struck by a lack of parity in institutional mobility, particularly between mothers' and fathers' experiences. In 2018, the University and College Union, the leading UK union for Higher Education, published a guidance document for working parents in the sector that argued that 'pregnant women and new mothers are experiencing discrimination in the workplace' (2018). Citing research from the Department for Business, Innovation and Skills, and the Equality and Human Rights Commission, the report argues that one in nine mothers reported feeling forced to leave their workplace, was dismissed or made redundant, and one in five mothers experienced harassment related to pregnancy or flexible work.

The Modern Families Index Report also argued that $41 \%$ of the mothers in the Index worked part-time, in comparison with 5\% of fathers (Working Families and Bright Horizons 2019). In the academic sector, white, male, cis colleagues are held accountable to different standards than everyone else, sustaining a patriarchal, colonial culture (Bhopal 2018; Gqola 2018). It is our experience too that the expectations keep changing, and they remain inconsistent. There is little attention paid to the extent to which certain forms of labour in academia, especially pastoral care, mostly performed by marginalised scholars, are both necessary and expected, but also invisible and deemed unequal.

In Mothers: An Essay on Love and Cruelty, Jacqueline Rose's fierce exploration of motherhood in Western discourse, she reminds us that motherhood is 'the place in our culture where we lodge, or rather bury, the reality of our own conflicts' (2018: 1). This is not only, argues Rose, played out through hollow discourses of mothers as a rare presence in public and political life, but also by the violence with which motherhood is treated, whilst also rejected, as a form of subjectivity. In early 2018, we saw this in the critical commentary surrounding New Zealand prime minister Jacinta Ardern bringing her daughter to work (at a recent United Nations summit), or taking flights separately from her government colleagues to facilitate breastfeeding (Swinson 2018). 
Motherhood is made to perform in ways that simultaneously celebrate its symbolic value and occlude or denigrate its lived experience. Motherhood is its own form of specificity, one that in academia particularly is periled with subtle forms of silencing: maternity pay or the lack thereof; check-in days; the expectation to work when not working; the return to work that assumes you carry on as normal; the fear and the truth that when you return to work, things will have moved on without you and survived without you; the return to work where you have to fight to demonstrate your worthiness of coming back; the expectation that once a mother, you have learnt to care, and therefore can be with care and dedication to the work, that you can manage. It is a paradoxical relation between feeling disposable and demanded to be resilient; being indispensable, yet stuck.

In The Undercommons, Stefano Harney and Fred Moten argue: 'What the beyond of teaching is really about, is not finishing oneself, not passing, not completing; it's about allowing subjectivity to be unlawfully overcome by others, a radical passion and passivity such that one becomes unfit for subjection, because one does not possess the kind of agency that can hold the regulatory forces of subjecthood' (2013: 36). There is a requirement in academia to take intellectual agency, but also to be compliant with structures at work; within this professional paradox, motherhood is both an invisible subject-position relegated to the domain of the personal, yet simultaneously deeply connected to caring duties at work, in both teaching and research. The institution needs us to be motherly, but not mothers.

The Undercommons encapsulates some of these problems. Harney and Moten provide this list of who might make up the undercommons of the academia: 'Maroon communities of composition teachers, mentorless graduate students, adjunct Marxist historians, out or queer management professors, state college ethnic studies departments, closed-down film programs, visa expired Yemeni student newspaper editors, historically black college sociologists, and feminist engineers.' They ask: what will the university say of them? 'It will say they are unprofessional. This is not an arbitrary charge. It is the charge against the more than professional.' (2013: 38) Who is considered 'unprofessional' in the neoliberal academy, on whose terms, and why? This neoliberal and patriarchal notion of 'professionalism' is thus precisely what needs to be unpacked in order to make space for collective resistance across marginalised communities.

In light of this recognition, we propose thinking of motherhood as a feminist strategy for survival.

\section{Motherhood as a feminist strategy}

Motherhood has taught us a lot about unseen difficulties, especially the subtlety of inclusion and diversity. In her article, 'Imposter Syndrome as a Public Feeling', Maddie Breeze speaks about impostor syndrome as a productive means of disrupting linear notions of success (2018: 210-11). In this disruption, and by making visible the challenges of motherhood, we recognise our new strategies: becoming unstuck feels deliciously possible. By being unstuck we can take on the impostor role more fully, as something that enables alternative approaches to thriving. Below are some of our strategies. 
First, we reframe motherhood not as a limited condition, but as a valuable, plural subjective experience that brings much to alternative means of knowledge-production, to embodiment and care. That is, we regard motherhood as a form of solidarity, but also as a form of knowing. The experience of motherhood is not a condition; it is a lens. Our bodies need to be present in all the complexities that come with that. Our embodied knowledge and our lens of motherhood allows for different ways of reading and responding to events in all contexts of our lives. All the disruptions which are, in fact, not disruptions at all, but rendered disruptive: we are difficult, because we are mothers. Within motherhood, other problems of identification are lodged - for example, of the gendered politics of care, and of the exclusion of gender non-binary and trans carers from parenting discourses - and thus motherhood becomes also a work of alliance that is desperately required in academia. Motherhood as a feminist strategy has to work in alliance with other experiences of parenting and care, and across marginalised communities.

Second, working collaboratively, listening to each other, rejecting competition in favour of the potential of common ground - these are newly trodden pathways and different methods of working that have shaped our doing and thinking as mothers. There is a potential in these new methods and pathways for unlocking different forms of understanding and knowledgemaking and sharing. There is something exciting about working with difference - we can be disruptive and difficult - and here is the possibility: we can disrupt the neoliberal/patriarchal and colonial oppression of the one 'right' way to write, publish, progress.

A third strategy for us has been giving space to this conversation, and finding other ways of facilitating conversation, solidarity and allyship across the different contexts of our academic work. This strategy includes locating formal or informal spaces to hold this conversation; sharing these experiences through podcasts or other social media platforms; working with colleagues who have moved into academic administration to re-calibrate new mothers' teaching and administration loads in order to enable space for research and learning and to negotiate new ways of working; and developing multiple signals of care and recognition towards each other.

An example of this strategy in action occurred at the ATHE conference in Boston in 2018, when one of us brought our infant son to listen to colleagues (including a PhD student and senior manager) sharing their research practice. Although his nappy change limited my full participation, I celebrated the joy of being in the room with both my son and my work, as well as the acknowledgment of my full self in that space. I celebrated the signalling of care that came from colleagues as they helped make that space happen in a safe and supportive way. We are not currently aware of any academic institutions that provide regular childcare support for early evening or daytime events in the UK, and we welcome suggestions of ways of working or examples to share back with our institutions.

Finally, we are practicing radical and mundane approaches to help manage the juggle. These include: no more meetings scheduled for pick-up time (prompting the 'shuffle of shame', where you attempt to slink out of the room because of childcare commitments); sharing techniques and phrases which enables you to just say 'no', without tangling yourself up in explanations; and supporting each other in rejecting the premise that we must be compliant. Instead, together we embrace being difficult and disruptive. 


\section{Postscript}

Gqola concludes her essay, 'A mothering feminist's life: A celebration, meditation and roll call', with the words of one her friends, explaining: 'I will never forgot what Xoliswa said, as I held her baby, because it freed me more than anything I have ever heard said about mothering':

My baby has a life, and will have a bigger life. I have a life. We are building our life together. She is not my life and I am not hers. I have a great life that I have worked quite hard to design just as it is. I have no intention of giving it up. It's a relationship of love and nurturing and guidance and responsibility and yes, there will be sacrifice, as there should be. But I will not sacrifice myself to motherhood. It would be a horrible thing to do to myself, and an injustice to my child. (Xoliswa in Gqola, 2018: 125)

This statement is, for us, a way in which to acknowledge the labour we put into the myriad work of daily life. Let us stand more proudly and loudly: let us own our new space, our interactions, and our ways of working as academic mothers.

\section{Bibliography}

Ahmed, S. (2004). The Cultural Politics of Emotion. London: Routledge.

Ahmed, S. (2017). 'Complaint as Diversity Work' in feministkilljoys, https://feministkilljoys.com/2017/11/10/complaint-as-diversity-work/

Arday, J and Mirza, H.S. (2018). Dismantling Race in Higher Education: Racism, Whiteness and Decolonising the Academy. London: Palgrave.

Bhopal, K. (2018). White Privilege: The Myth of a post-racial society. London: Policy Press.

Breeze, M. (2018). 'Imposter Syndrome as a Public Feeling.' In Yvette Taylor and Kinneret Lahad (eds.), Feeling Academic in the Neoliberal University: Feminist Flights, Fights and Failures. Basingstoke: Palgrave Macmillan, pp. 191-219.

Evans, M. (2010). 'Coercion and consensus in higher education' in Learning and Teaching in the Social Sciences 3(2), pp39-54.

Gabriel, D. and Tate, S. (2017). Inside the Ivory Tower: Narratives of women of colour surviving and thriving in British academia. London: Trentham Books.

Gqola, P. M. (2018). Reflecting Rogue: Inside the mind of a feminist. Auckland Park, South Africa: MFBooks Joburg.

Harney, S. and Moten, F. (2013). The Undercommons: Fugitive Planning \& Black Study. Wivenhoe/New York: Minor Compositions.

Lynch, K. (2010).'Neoliberalism and marketisation: the implications for higher education' in European Education Research Journal, 5(1), pp 1-17

Morrish, L. (2015). 'Gender and Performance in the Neoliberal Academy' in academicirregularities, https://academicirregularities.wordpress.com/2015/07/03/gender-and-performancein-the-neoliberal-academy/

Rose, J. (2018). Mothers: An Essay on Love and Cruelty, Faber \& Faber.

Swinson, J. (2018). 'Like me, Jacinda Ardern took her baby to work - and was met with ignorance', The Guardian, September 28, 
https://www.theguardian.com/commentisfree/2018/sep/28/iacinda-ardern-babywork-new-zealand-prime-minister-motherhood

Sutherland, J. (2010). 'Mothering, Guilt and Shame' in Sociology Compass, 5.5 https://onlinelibrary.wiley.com/doi/abs/10.1111/j.1751-9020.2010.00283.x

Tzanakou, C. (2019) 'Moderate feminism within or against the neoliberal university? The example of Athena SWAN' in Gender, Work and Organisation. 13.1. https://onlinelibrary.wiley.com/doi/full/10.1111/gwao.12336

University and College Union. (2018) 'Working Parents: an Equality Guide for branches and reps', https://www.ucu.org.uk/media/9249/Working-parents---an-equality-guide-forbranches-and-reps/pdf/Working parents A4 booklet Jan 18.pdf

Working Families and Bright Horizons. (2019). 'Modern Families Index 2019: Summary Report', https://www.workingfamilies.org.uk/wpcontent/uploads/2019/02/BH MFI Summary Report 2019 Final.pdf 